\title{
CORRECTION
}

\section{Correction to: Gender, the gender gap, and their interaction; analysis of relationships with children's mental health problems}

\author{
Vivianne Kovess-Masfety ${ }^{1}$ (D) Miriam J. Woodward ${ }^{2} \cdot$ Katherine Keyes $^{2} \cdot$ Adina Bitfoi $^{3} \cdot$ Mauro Giovanni Carta $^{4}$. \\ Ceren Koç ${ }^{5}$ Sigita Lesinskiene ${ }^{6} \cdot$ Zlatka Mihova $^{7} \cdot$ Roy Otten $^{8} \cdot$ Mathilde Husky $^{9}$
}

Published online: 15 October 2021

(c) Springer-Verlag GmbH Germany, part of Springer Nature 2021

\section{Correction to: \\ Social Psychiatry and Psychiatric Epidemiology \\ (2021) 56:1049-1057 \\ https://doi.org/10.1007/s00127-020-01950-5}

In the original publication of the article, the first author family name has been incorrectly published. The correct author name is given in this erratum.

The original article was corrected.

The original article can be found online at https://doi.org/10.1007/ s00127-020-01950-5.

Vivianne Kovess-Masfety

vkovess@gmail.com

1 University of Paris, LPPS, Paris, France

2 Mailman School of Public Health, Columbia University, New York, NY, USA

3 The Romanian League for Mental Health, Bucharest, Romania

4 Centro di Psichiatria di Consulenza e Psicosomatica Azienda Ospedaliero Universitaria di Cagliari, Cagliari, Italy

5 Yeniden Health and Education Society, Istanbul, Turkey

6 Clinic of Psychiatry, Faculty of Medicine, University of Vilnius, Vilnius, Lithuania

7 New Bulgarian University, Sofia, Bulgaria

8 Behavioural Science Institute, Pluryn, Research and Development, Radboud University Nijmegen, Nijmegen, The Netherlands

9 Laboratoire de Psychologie EA4139, Université de Bordeaux, Bordeaux, France 